\title{
Factors Affecting the Behavioral Intention and Behavior of Using E-Wallets of Youth in Vietnam
}

\author{
Trong Nhan PHAN ${ }^{1}$, Truc Vi HO², Phuong Viet LE-HOANG ${ }^{3}$
}

Received: July 18, 2020 Revised: August 23, 2020 Accepted: August 28, 2020

\begin{abstract}
The study examines an empirical case that explores the key constructs of the Unified Theory of Acceptance and Use of Technology (UTAUT) (Venkatesh, Morris, Davis \& Davis, 2003) and the relationship between security and privacy of the Theory of Perceived Risk (TPR) (Bauer, 1960). This study employs survey data of 200 young Internet users aged 18 to 25 . The study was conducted through two steps: preliminary research by qualitative research method to form the official research scale then formal research by quantitative research method using CFA and SEM to test the research model. The research results show that performance expectancy and social influence significantly predict behavioral intention to use e-wallets in payment. In contrast, the factors, namely, security and privacy, and effort expectancy, are statistically insignificant on behavioral intention. Nevertheless, the facilitating conditions factor still affects the behavior of using e-wallets. The study proposes a model to generalize the online payment environment through the integration of UTAUT and TPR models that are important for online payment management and researchers in the technology environment. The findings of this study suggest that social influence significantly affects the intention of young people to use e-wallets instead of security and privacy.
\end{abstract}

Keywords: Behavioral Intention, E-Wallets, Unified Theory of Acceptance and Use of Technology

JEL Classification Code: M1, M3, O3

\section{Introduction}

Current spending trends of Vietnamese consumers, with $53 \%$ of the population using the Internet, that is nearly 50 million subscribers using smartphones, record the demand for clothing shopping (53\%), followed by tourism (48\%), and leisure activities (46\%). Especially for the young generation, the demand for low-cost technology transportation and online ordering of drinks and food are always of primary interest. With a high percentage of young people, this is

${ }^{1}$ First Author and Corresponding Author. Lecturer, Industrial University of Ho Chi Minh City, Vietnam [Postal Address: 12 Nguyen Van Bao Street, Ward 4, Go Vap District, Ho Chi Minh City, 700000, Vietnam] Email: phantrongnhan@iuh.edu.vn

${ }^{2}$ Lecturer, Industrial University of Ho Chi Minh City, Vietnam.

Email: hotrucvi@iuh.edu.vn

${ }^{3}$ Lecturer, Graduate School, Ho Chi Minh City Open University, Vietnam. Email: lehoangvietphuong@gmail.com

(c) Copyright: The Author(s)

This is an Open Access article distributed under the terms of the Creative Commons Attribution Non-Commercial License (https://creativecommons.org/licenses/by-nc/4.0/) which permits unrestricted non-commercial use, distribution, and reproduction in any medium, provided the original work is properly cited. a fertile market for services in a digital economy where e-wallets are a possible method of payment. According to statistics from the State Bank of Vietnam (2018), there were 26 payment service providers licensed in Vietnam, of which the majority were e-wallets, the favorites being MoMo and Zalo Pay, GrabPay by Moca, Viettel Pay, and AirPay. Those kinds of payment systems meet the needs of Internet users in the context of rapidly developing e-commerce: diverse, quick and convenient forms of recharge, and payment including websites and mobile applications, which customers can manipulate through a few simple operations wherever and whenever (Nguyen, Nguyen \& Cao, 2014).

Nevertheless, Vietnam had the lowest non-cash transaction volume in the Asian region (4.9\%) while this rate is $26.1 \%$ in China, $59.7 \%$, in Thailand, and reaches $89 \%$ in Malaysia (World Bank, 2018). Hence, the habit of using cash is still widespread, and most Vietnamese find e-wallets are new-fangled and have many concerns with these online payment tools. In the context of the Industrial Revolution 4.0, the Government of Vietnam is now aiming to increase the share of non-cash payment towards a digital economy. However, there are barriers that suppliers of payment tools through e-wallets need to manage. According to Nguyen 
et al., (2014), there are not many communities using them due to the consumption habits of most people in Vietnam who still prefers cash-on-delivery (COD) payment method; Internet users do not trust online payment services. The authors also pointed out the lack of synchronization and linking among suppliers for money transfers by e-wallets between banks, which are quite tricky. Furthermore, the integration of e-wallets with business systems on the market are not widely available; the lack of versatility where each type of e-wallets only incorporates a few features is also a common barriers causing the low ratio of using e-wallets in Vietnam.

With e-wallets payment procedure in Vietnam as the application field, this study focused on empirically identifying the precise impacts of security and privacy of the TPR model on the core construct of the Unified Theory of Acceptance and Use of Technology (UTAUT), and thereby validating an extended UTAUT in a new context, from the manufacturing to the online payment method service domain. With this study, the researchers can widen the perspective to another aspect of user adoption of technology based on the potential benefits and risks.

\section{Literature Review}

Behavioral intent is a manifestation of each person's willingness to perform a behavior (Fishbein \& Ajzen, 1975). It is considered as the direct premise leading to behavior according to the Technology Acceptance Model (TAM) of Fishbein and Ajzen (1975). According to Venkatesh et al., (2003), the Unified Theory of Acceptance and Use Technology (UTAUT) are proposed to take into account technological adoption. More specifically, UTAUT is a combination of theories ranging from rational action theory, technology acceptance model, planned behavioral theory, diffusion of innovation theory, and social cognitive theory. In particular, behavioral intent is built on eight scales with performance expectations, effort expectations, and social factors that have a direct impact on behavioral intent and direct determinants of behavior are the favorable conditions. Williams, Rana, Dwivedi and Lal (2011) applied the UTAUT theory to test a range of technologies (Junadi \& Sfenrianto, 2015; Slade, Dwivedi, Piercy \& William, 2015) rediscovering various online payment tools. This research also focuses on the topic of technology adoption; therefore, it is theoretical and practical to use UTAUT as a theoretical basis for this study. The four vital independent constructs applied in this study are the same as the original UTAUT theory. The authors strongly believe that in order to accept a new technological payment method likes e-wallets, Vietnamese users would have to consider those kinds of elements.

UTAUT was proposed in 2003; the focus of other authors' research on the application of the theory of UTAUT extended through the modification and addition of observed variables as well as ladders. Other measurements were considered besides combining with other theoretical models. The authors focus on redefining the causal relationship in other models with the UTAUT variables. In this paper, the researchers have paid special attention to combining these variables through the Theory of Perceived Risk (TPR) proposed by Bauer (1960). Bauer suggests that benefits are often associated with perceived risk in consumer behavior in which the risk mentioned in TPR theory is a perceived risk. Six types of cognitive risks have been studied in the context of personal behavior, including information security risks, personal privacy risks, financial risks exits, risks associated with social relationships, time/convenience risks, and performance risks. According to Ostlund (1974) these risks are considered as barriers to the creation of initiatives. E-wallet is an element of innovation in consumer payment technology and it carries many potential risks about which customers worry both directly and indirectly, so this theory is suitable for this study. In Vietnam's online payment market, there has not been any proper experimental research published on the intention of using e-wallets. According to this researcher, results confirm that security and privacy are the factors demonstrating the limitations of the development of electronic payment. This point of view has also been tested by research in the fields of online purchase intention in Vietnam (Ha \& Nguyen, 2016), mobile banking services in Rwanda (Issac \& Michael, 2015) or e-payment system in Indonesia (Junadi \& Sfenrianto, 2015). The element of TPR applied in this study are security and privacy.

\section{Hypotheses}

\subsection{Security and Privacy}

According to Donald and Rémy (2012), the security of e-wallets is defined as the degree to which customers believe that using a specific payment method via the mobile application will be kept safe. Security is related to authentication, information verification, and data security (Chen, 2008). Privacy and security also increase the consumer experience, and it also significantly affects customers in the risks involved (Tran, 2020). Besides, the privacy of e-wallets is the rights where customers expect their information and transactions to be kept confidential (Chen, 2008). It consists of keeping information intact, without unauthorized access, and no use of private information for secondary purposes. According to Liu and Pham (2016), when customers trust mobile payment method, they relate to the honesty and trustworthiness of service providers, then, will increase their intention to use the system. Donald and Rémy (2012) have shown that security and privacy in personal information positively affect behavioral intention. 


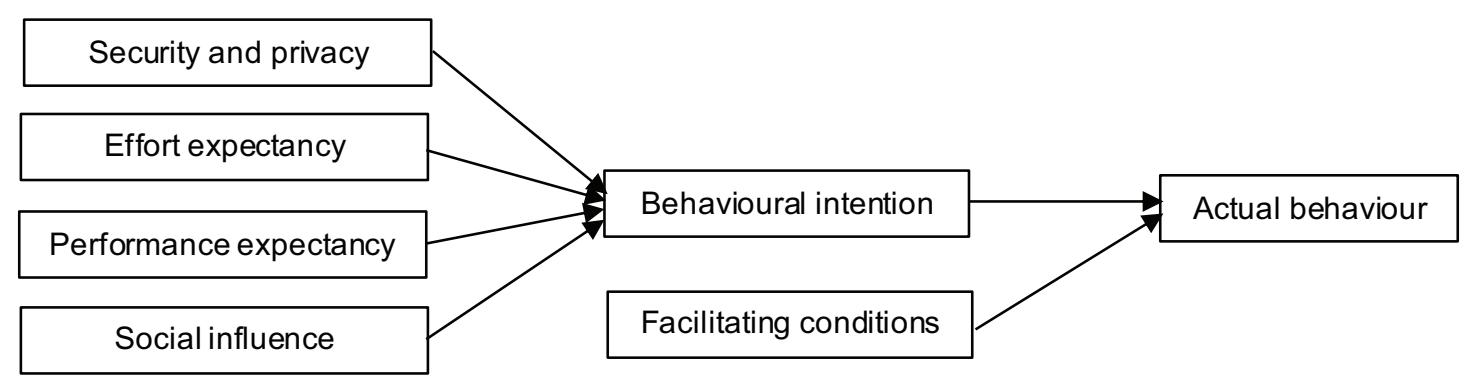

Figure 1: Research model proposed by the authors

H1: Security and privacy have a positive influence on the intention of using e-wallets.

\subsection{Effort Expectancy}

The effort expectancy refers to the way the system is used efficiently. It includes users interacting with the system clearly and in a easily understandable manner, and is easy to use (Venkatesh et al., 2003). Besides, Junadi and Sfenrianto (2015) used the scale of effort expectancy, including easy-touse payment systems, flexible transactions and easy-to-learn payment systems. It is considered that these scales are quite adequate for research. According to Nguyen et al. (2014), the less effort you make in using e-wallets, the more you intend to use it.

H2: Effort expectancy has a positive influence on the intention of using e-wallets

\subsection{Performance Expectancy}

The performance expectancy of e-wallets is the extent to which users believe that using e-wallets will help them achieve high performance in payment methods (Venkatesh et al., 2003). According to Junadi and Sfenrianto (2015) performance expectancy is when a customer receives more benefits than via traditional payment methods. Expected performance is considered from the perspective of transaction productivity, convenience in transactions and speed in transactions. and Sfenrianto (2015); Venkatesh et al. (2003) have shown that the intention to use the e-wallet payment method is beneficial in all the customer's work. From there, the hypothesis is set as follows:

H3: Performance expectancy has a positive effect on a customer's e-wallet intent

\subsection{Social Influence}

Social influence is defined as the extent to which users perceive that people are essential, and have a close relationship with them, giving advice and believing that they should use it (Venkatesh et al., 2003). More specifically, essential people are fishy sisters, parents in the family or those with close relations such as friends, relatives in the family, or influential people who think that individuals should apply technological systems (Venkatesh et al., 2003; Junadi \& Sfenrianto, 2015). Besides, with the steady development of technology and digital media as well as social networks, individuals are also heavily influenced by groups and communities (Nguyen et al., 2014; Han, 2020). Venkatesh et al. (2003) show that social influence is one of four factors that directly and positively influence customer intentions. Individuals tend to be influenced by advice or feedback from people in the early stages of using technology without having enough experience and belief. From there, the hypothesis is set as follows:

H4: Social influence has a positive influence on users' intention to use e-wallets

\subsection{Behavioral Intention}

Behavioral intent is the best factor to predict a correct behavior (Fishbein \& Ajzen, 1975). Accordingly, the intention is expressed in the readiness of the user to use the product/service (Venkatesh et al., 2003). When researching the intention of using e-wallets in payment, the content focused on the scale including the intention to use, plan to use and predict system usage (Venkatesh et al., 2003). As with previous studies, consumer attitudes were strong and positively influencing purchase intentions. Besides, Kim and Won (2020) concur that the consumer attitude toward the product and service had a statistically significant effect on purchase intention. The intention to use technological systems has a significant correlation with user behavior (Fishbein \& Ajzen, 1975). It means that the higher the intention the consumer is likely to have, the higher the actual behavior and vice versa, so the proposed hypothesis is as follows:

H5: Intention of behavior has a positive effect on actual behavior. 


\subsection{Facilitating Conditions}

Facilitating conditions are ways individuals believe the technical and organizational infrastructures will assist in adapting and using the technology system conveniently. When studying facilitating conditions, Venkatesh et al. (2003) explored and identified relevant content including the essential resources available to use the system as knowledge, compatibility with other systems, and a specific person (or group) is available to assist, so the hypothesis is:

H6: Facilitating conditions have a positive effect on actual behavior

\subsection{Actual Behaviour}

According to Al-Gahtani (2001); Davis (1989), the use of information systems is seen as an indicator of success in technology application. Therefore, the use of e-wallets in payment for shopping transactions, in particular, the actual behavior acts as a dependent variable in the model, which is consistent with studies by Legris, Ingham and Collerette (2003). Frequency of use is seen as an effective way to analyze actual user behavior (Kim \& Gyo, 2008) and it is also considered an essential factor to study user behavior related to technology application in operation (Jiajun \& Carl, 2005; Mohamed \& Tarek, 2013). In addition to looking at frequency, the actual behavior also considers comfort and positivity in using digital wallets (Davis, Bagozzi \& Warshawm, 1989; Davis, 1989; Al-Gahtani, 2001).

\section{Research Methodology}

The study was conducted through two steps: preliminary research and formal research. Preliminary research by a qualitative method was designed to understand whether the interviewee understands the content, as well as complement, add, edit or remove statements to form the official ladder. Formal research used quantitative methods such as Cronbach's Alpha coefficient analysis for each unidirectional scale. Then analysis of EFA elements with Promax rotation to reflect the more fundamental data structure. Next, the author performed a confirmatory factor analysis (CFA) and tested the SEM linear structure model to assess the relevance of the research model. This study uses questionnaire interview techniques designed on the Google Docs Form with 200 youth users aged 18 to 25 . By random sampling method, the sample was made up of $42.5 \%$ of men and $57.5 \%$ of women.

In order to carry out the research, the author initially inherited the scales of other studies related to the specific sources cited as follows:

\section{Results}

\subsection{Reliability Test}

After running the Cronbach's Alpha reliability test, the results showed that two observed variables of the Security and Privacy (SP) scale were removed as SP1 and SP2 because the total correlation coefficient was less than 0.3 , and Cronbach's Alpha delete is higher than Cronbach's Alpha total of scale. Besides, the observed variables for other scales are accepted and suitable for EFA analysis. The following table shows the detailed results.

\subsection{Exploratory Factor Analysis (EFA) and Confirmatory Factor Analysis (CFA)}

In EFA analysis, the author uses Promax rotation to group components with $\mathrm{KMO}$ result of 0.760 , and sig $=0.00$ $<0.05$, so all variables in each component are correlated with each other. Besides, the total variance is $=72.119 \%$, which means that the observed variables explain $72.119 \%$ of the change in actual behavior. Also, the rotation matrix results show a factor loading $>0.5$, and it can be divided into six components.

The confirmatory factor analysis (CFA) result shows that Chi-square $/ \mathrm{df}=1.127<3$; CFI $=0,986>0.9$; GFI $=$ $0.901>0.9$; TLI $=0.983>0.9$ and RMSEA $=0.025<0.08$. It means that this model is suitable for market data. Furthermore, the Standardized Regression Weights results described the composite reliability and variance extracted (meet the requirement $(>0.5)$. The standardized weights of estimate were greater than 0.5 ; the regression weights were statistically significant $(\mathrm{P}=0.00)$ with $95 \%$ confidence, so the observed variables are used to measure concepts that achieve convergent values. There is no correlation between all scales and errors, so the observed variables realize unidirectional.

\subsection{Structural Equation Modeling (SEM)}

The results of SEM (standardized) was indiced (Chisquare $/ \mathrm{df}=1.160<3 ; \mathrm{CFI}=0.981>0.9 ; \mathrm{TLI}=0.978>0.9$; RMSEA $=0.028 \leq 0.08$ ). So, the model's fit conditions meet requirement.

The results of hypothesis testing are shown on Table 4. The regression weights show that social influence (SI) and performance expectancy (PE) affect intention behavioral, which get $95 \%$ of statistical significance with $\mathrm{P}<0.05$. In particular, facilitating condition factors also affect actual behavior with statistical significance $(\mathrm{P}=0.02<0.05)$. Thus, research hypotheses including H3 (Performance expectancy 
Table 1: Design Scale

\begin{tabular}{|c|c|c|}
\hline Code & Scale & Source \\
\hline \multicolumn{3}{|c|}{ Security and Privacy_SP } \\
\hline SP1 & E-wallets payment system ensures information verification among participating parties & \multirow{6}{*}{ Chen (2008) } \\
\hline SP2 & $\begin{array}{l}\text { I believe that the e-wallets payment system always has a plan to prepare to deal with } \\
\text { risks and ensure data security }\end{array}$ & \\
\hline SP3 & E-wallets payment system ensures to keep my information intact & \\
\hline SP4 & I believe that my personal information will not be used for other purposes & \\
\hline SP5 & I believe that my private transactions via e-wallets will be protected & \\
\hline SP6 & I believe that my personal information is protected via e-wallets database & \\
\hline \multicolumn{3}{|c|}{ Effort Expectancy_EE } \\
\hline EF1 & E-wallets payment is easy to use & $\begin{array}{l}\text { Junadi and Sfenrianto } \\
\text { (2015) }\end{array}$ \\
\hline EF2 & I can interact with the e-wallets system clearly & Venkatesh et al. (2003) \\
\hline EF3 & E-wallets payment is easy to learn & \multirow{2}{*}{$\begin{array}{l}\text { Junadi and Sfenrianto } \\
\qquad(2015)\end{array}$} \\
\hline EF4 & E-wallets payment helps me be flexible in transactions & \\
\hline EF5 & I can proficiently use the e-wallets payment & Venkatesh et al. (2003) \\
\hline \multicolumn{3}{|c|}{ Performance Expectancy_PE } \\
\hline PE1 & Using e-wallets increases my work productivity & Venkatesh et al. (2003) \\
\hline PE2 & Using e-wallets payment is more convenience & $\begin{array}{l}\text { Junadi and Sfenrianto } \\
\qquad(2015)\end{array}$ \\
\hline PE3 & Using e-wallets payment allows me to make transactions faster than cash payment & Venkatesh et al. (2003) \\
\hline \multicolumn{3}{|c|}{ Social Influence_SI } \\
\hline $\mathrm{SI} 1$ & Important people (family / relatives / friends) are using e-wallets payment & $\begin{array}{l}\text { Junadi and Sfenrianto } \\
\text { (2015) }\end{array}$ \\
\hline $\mathrm{SI} 2$ & Influential people are using e-wallets payment & Venkatesh et al. (2003) \\
\hline SI3 & Communities which I take part in are using e-wallets payment & Nguyen et al. (2014) \\
\hline \multicolumn{3}{|c|}{ Facilitating Conditions_FC } \\
\hline FC1 & I have smartphone to use e-wallets payment & \multirow{4}{*}{ Venkatesh et al. (2003) } \\
\hline FC2 & I have enough knowledge to use e-wallets payment & \\
\hline FC3 & $\begin{array}{l}\text { I have received support and guidance from suppliers on issues related to the use of } \\
\text { e-wallets payment }\end{array}$ & \\
\hline FC4 & $\begin{array}{l}\text { Famous people (family/relatives/ friends) help me use e-wallets payment when I meet } \\
\text { difficulties }\end{array}$ & \\
\hline \multicolumn{3}{|c|}{ Behavioural Intention_IB } \\
\hline IB1 & I have intended to use an e-wallets & \multirow{2}{*}{$\begin{array}{l}\text { Carlsson, Walden and } \\
\text { Nikravesh (2006) }\end{array}$} \\
\hline IB2 & I have a plan to use an e-wallets & \\
\hline IB3 & I have a prediction of the use of e-wallets & Patrick (1996) \\
\hline \multicolumn{3}{|c|}{ Actual Behavior_AB } \\
\hline AB1 & I use e-wallet payment regularly & $\begin{array}{l}\text { Mohamed and Tarek } \\
\text { (2013) }\end{array}$ \\
\hline $\mathrm{AB2}$ & Using e-wallet is pleasant & \multirow{2}{*}{ Al-Gahtani (2001) } \\
\hline AB3 & Using e-wallet is positive & \\
\hline
\end{tabular}


Table 2: Cronbach's Alpha Results

\begin{tabular}{|l|c|l|c|}
\hline Scale & Cronbach's Alpha & Scale & Cronbach's Alpha \\
\hline Security and Privacy_SP & 0.813 & Facilitating Conditions_FC & 0.887 \\
\hline Performance Expectancy_PE & 0.834 & Behavioural Intention_IB & 0.846 \\
\hline Effort Expectancy_EE & 0.848 & Actual Behavior_AB & 0.830 \\
\hline Social Influence_SI & 0.840 & - & - \\
\hline
\end{tabular}

Table 3: The Standardized Regression Weights Results

\begin{tabular}{|l|c|c|l|c|c|}
\hline Scale & The composite reliability & Variance extracted & Scale & The composite reliability & Variance extracted \\
\hline EE & 0.849 & 0.530 & SI & 0.839 & 0.635 \\
\hline FC & 0.906 & 0.706 & PE & 0.842 & 0.641 \\
\hline SP & 0.821 & 0.539 & AB & 0.832 & 0.624 \\
\hline IB & 0.850 & 0.655 & - & - & - \\
\hline
\end{tabular}

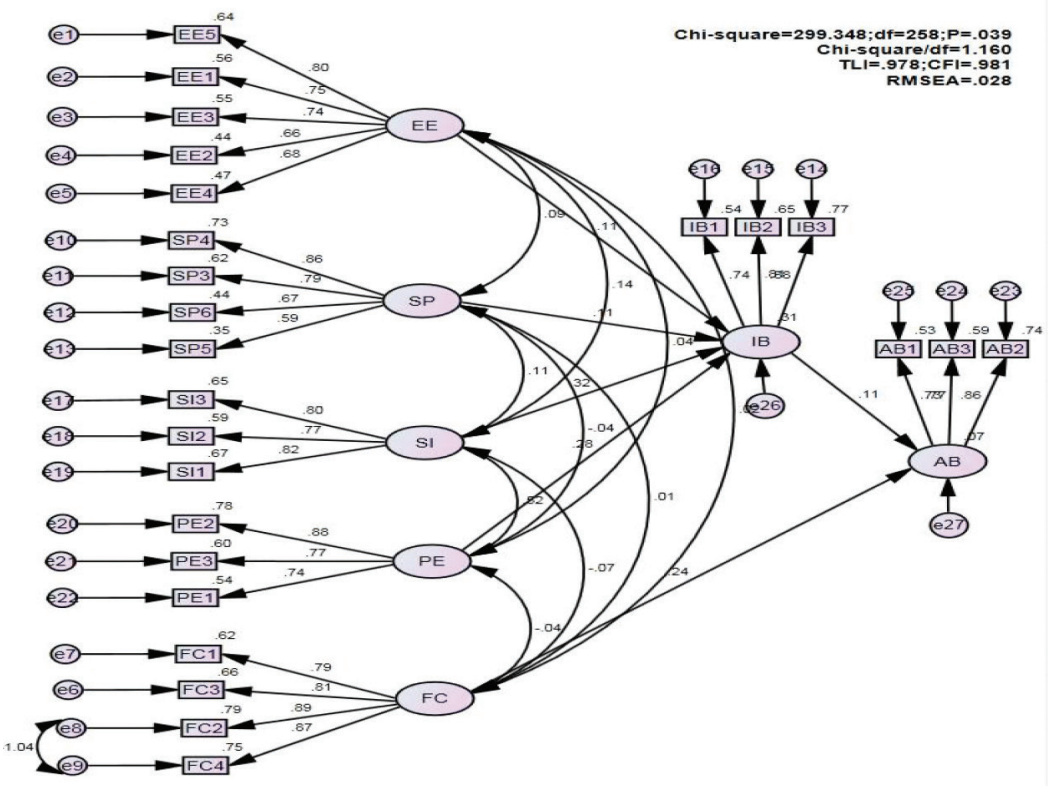

Figure 2: The results of SEM (standardized)

Table 4: Hypothesis testing

\begin{tabular}{|l|l|c|c|c|c|c|}
\hline \multicolumn{7}{|c|}{ Regression Weights } \\
\hline & & & Estimate & SE. & CR. & P \\
\hline IB & $<---$ & EE & 0.113 & 0.077 & 1.471 & 0.141 \\
\hline IB & $<---$ & SP & 0.108 & 0.073 & 1.481 & 0.139 \\
\hline IB & $<---$ & SI & 0.345 & 0.102 & 3.372 & $* * *$ \\
\hline IB & $<---$ & PE & 0.258 & 0.084 & 3.054 & 0.002 \\
\hline AB & $<---$ & FC & 0.199 & 0.064 & 3.129 & 0.002 \\
\hline AB & $<---$ & IB & 0.108 & 0.076 & 1.413 & 0.158 \\
\hline
\end{tabular}

\begin{tabular}{|c|c|c|c|}
\hline \multicolumn{4}{|c|}{ Standardized Regression Weights } \\
\hline & & & Estimate \\
\hline IB & $<---$ & EE & 0.108 \\
\hline IB & $<---$ & SP & 0.109 \\
\hline IB & $<---$ & SI & 0.318 \\
\hline IB & $<---$ & PE & 0.278 \\
\hline AB & $<---$ & FC & 0.238 \\
\hline AB & $<---$ & IB & 0.114 \\
\hline
\end{tabular}


$\rightarrow$ Intention of using e-wallets), H4 (Social influence $\rightarrow$ Intention of using e-wallets) and H6 (Facilitating conditions $\rightarrow$ Actual behaviour) are accepted. The other hypotheses are rejected with statistical insignificance $(\mathrm{P}>0.05)$, namely, H1 (Security and privacy $\rightarrow$ Intention of using e-wallets), H2 (Effort expectancy $\rightarrow$ Intention of using e-wallets) and H5 (Intention of using e-wallets $\rightarrow$ Actual behaviour). Besides, the table standardized regression weights indicate that all coefficients are positive. Below is a detailed table of significance level and impact level of the scales:

\section{Discussion}

Through the research results, we see that the intention of using e-wallets in payment by young Vietnamese is greatly motivated by social influence and expected performance. However, to generate real user behavior, a core factor that is put on top is favourable conditions. Besides, the results tell us that young people do not care about security and privacy, nor do they care about how easy or difficult it is to use the system. It is only because young people are known to be customers who adapt well to technology and have the ability to learn quickly.

Therefore, creating a useful payment application, suitable for customers, to help them satisfy their needs and achieve expectations is necessary. Besides, research to understand what customers want and need is something that application development businesses need to care about. Young people are also greatly impacted by influential groups (such as relatives, friends, celebrities). A marketing campaign that employs public influencers is also a bright spot in strategic planning to attract customers. Besides, building trust and love of customers who have used the product by word of mouth operation is also a potential step for businesses to promote sales activities. However, the difficulty for young people to use e-wallets is rooted in the fact that the facilities and equipment such as phones, wifi networks, or bank cards linked to online payment or registration Internet must be ready. If it is possible to link to support customers in terms of physical conditions as well as customers with the right conditions, surely customers will be willing to use e-wallets in payment. Specific solutions are as follows:

Social Influence is the most potent factor affecting the intention of behavior. Accordingly, if the online payment service provider devises advertising campaigns for e-wallets with the cooperation of celebrities, they will increase consumer awareness of products according to the strategy approach to young people. If an advertising program is good enough, it will create the effect of spreading through social networks. Besides, programs that invite friends to join, download, and use e-wallets with special offers will maximize efficiency. The results of the impact analysis through the regression equation show that expected performance is the second factor that has a substantial impact on behavioral intent. E-wallet application providers need to focus on developing and expanding the interconnected utilities. There is a need to cooperate with partners who provide functions such as travel, eating, medical treatment, etc., creating an ecosystem to bring various features to meet the needs of users. Convenient service will help users increase the experience and feel the useful value of e-wallet. Moreover, Facilitating Conditions is a factor that has a direct impact on the use of e-wallets. Linking with mobile phone partners provided in Vietnam to be able to integrate applications into the menu bar is a solution that administrators need to consider. However, to do this, the e-wallet must be a popular application to have the opportunity to link with popular manufacturers and operating systems on the market.

\section{Conclusions}

The study proposes a model to generalize the online payment environment through the integration of UTAUT and TPR models that are important for online payment management and researchers in the technology environment. Data analyzed from 200 customers yielded essential findings that partially support the research hypotheses. The research results show that social influence significantly affects the intention of young people to use e-wallets instead of security and privacy. However, the research still has certain limitations. First, the results show that the proposed model has low explanatory power. This finding may be particularly valuable to researchers, including more variables than UTAUT and TPR when predicting intent and behavior using electronic payment. Also, some moderation effects may not be presented in the research model. Therefore, in the future, the study should expand the UTAUT and TPR models by adding essential factors to increase the predictive power of the model in the context of electronic payments. Finally, future research may consider the behavioral intent and e-payment behaviour of the elderly.

\section{References}

Al-Gahtani, S. (2001). The applicability of TAM outside North America: An empirical test in the United Kingdom. Information Resources Management Journal, 14(3), 37-46.

Bauer, R. A. (1960). Consumer Behavior as Risk Taking. In: Hancock, R.S., Ed., Dynamic Marketing for a Changing World, Proceedings of the 43rd Conference of the American Marketing Association (pp. 389-398). Chicago, Illinois.

Chen, L. (2008). A model of consumer acceptance of mobile payment. International Journal of Mobile Communications, $6(1), 32-52$.

Davis, F. D. (1989). Perceived usefulness, perceived ease of use, and user acceptance of information technology. The Management Information Systems Quarterly, 13(3), 318-339. 
Davis, F. D., Bagozzi, R. P., \& Warshaw, P. R. (1989). User acceptance of computer technology: A comparison of two theoretical models. Management Science, 35, 982-1002.

Donald, L. A., \& Rémy, M.-W. (2012). Building a Research Model for Mobile Wallet Consumer Adoption: The Case of Mobile Suica in Japan. Journal of Theoretical and Applied Electronic Commerce Research, 7(1), 94-110.

Fishbein, M., \& Ajzen, I. (1975). Belief, Attitude, Intention, and Behavior: An Introduction to Theory and Research. Reading, MA: Addison-Wesley.

Ha, T. N., \& Nguyen, D. T. (2016). Factors Influencing Vietnamese Consumers' Online Shopping Intention: An Extension of the Theory of Planned Behavior. VNU Journal of Science, 32(4), 21-28.

Han, J. H. (2020). The Effects of Personality Traits on Subjective Well-being and Behavioral Intention Associated with Serious Leisure Experiences. Journal of Asian Finance, Economics and Business, 7(5), 167-176. https://doi.org/10.13106/jafeb.2020. vol7.no5.167.

Issac, M. A., \& Michael, M. N. (2015). Effectiveness of Mobile Banking Services in Selected Commercial Banks in Rwanda. Journal of Applied Economics and Business, 3(2), 49-60.

Jackson, C. M., Chow, S., \& Leitch R. (1997). Toward an Understanding of the Behavioural Intention to Use an Information System. Decision Sciences, 28(2), 357-389. https:// js.vnu.edu.vn/EAB/article/view/3877.

Jiajun, J. C., \& Carl, A. (2005). User Acceptance of Mobile Payments: A Theoretical Model for Mobile Payments. Proceedings of the Fifth International Conference on Electronic Business. Hong Kong.

Junadia, \& Sfenrianto. (2015). A Model of Factors Influencing Consumer's Intention to Use E-Payment System in Indonesia. Procedia Computer Science, 59, 214-220.

Kim, Y., \& Gyo, C. M. (2008). Personalised information services using a hybrid recommendation method based on usage frequency. Program, 42(4), 436-447.

Legris, P., Ingham, J., \& Collerette, P. (2003). Why do people use information technology? A critical review of the technology acceptance model. Information \& Management, 40, 191-204.

Mohamed, A. G., \& Tarek, R. (2013). Mobile Banking Adoption: An Examination of Technology Acceptance Model and Theory of Planned Behavior. International Journal of Business Research and Development, 2(1), 35-50.

Nielson. (2018). Consumer Confidence Index Q3 2018 Vietnam. Retrieved July 20, 2020, from https://www.nielsen.com/vn/vi/ insights/2018/consumer-confidence-index-q3-2018-vietnam. html

Nguyen, D. T., Nguyen, T. D., \& Cao, T. H. (2014). Acceptance and Use of Cloud-based E-learning. Journal of Science and Technology Development, 17(Q3), 69-84.

Ostlund, L. (1974). Perceived innovation attributes as predictors of innovativeness. Journal of Consumer Research, 1(2), 23-29.

Slade, E. L., Dwivedi, Y. K., Piercy, N. C., \& Williams, M. D. (2015). Modeling Consumers' Adoption Intentions of Remote Mobile Payments in the United Kingdom: Extending UTAUT with Innovativeness, Risk, and Trust. Psychology and Marketing, 32(8), 860-873.

The State Bank of Vietnam. (2018). Annual Report 2017. Retrieved July 20, 2020, from https://www.sbv.gov.vn/ webcenter/ShowProperty?nodeId=/UCMServer/SBV355222// idcPrimaryFile\&revision=latestreleased.

Tran, V. D. (2020). The Relationship among Product Risk, Perceived Satisfaction and Purchase Intentions for Online Shopping. Journal of Asian Finance, Economics and Business, 7(6), 221231. https://doi.org/10.13106/jafeb.2020.vol7.no6.221.

Venkatesh, V., Morris, G. M., Davis, B. G., \& Davis, D. F. (2003). User Acceptance of Information Technology: Toward A Unified View. MIS Quarterly, 27(3), 425-478.

Williams, M., Rana, N., Dwivedi, Y., \& Lal, B. (2011). Is UTAUT really used or just cited for the sake of it? A systematic review of citations of UTAUT's originating articles. Proceedings of the European Conference on Information Systems. Helsinki, Finland.

Won, J., \& Kim, B. Y. (2020). The Effect of Consumer Motivations on Purchase Intention of Online Fashion - Sharing Platform. Journal of Asian Finance, Economics and Business, 7(6), 197207. https://doi.org/10.13106/jafeb.2020.vol7.no6.197.

World Bank. (2018). The World Bank Annual Report 2018 (English). Retrieved July 20, 2020, from http://documents. worldbank.org/curated/en/630671538158537244/The-WorldBank-Annual-Report-2018. 